\title{
LA PERCEPCIÓN DE LA FIGURA DEL CONQUISTADOR EN TEXTOS HISPANOAMERICANOS DE LOS SIGLOS XVIII Y XIX
}

\author{
VIRGINIA GIL AMATE
}

No es mi intención deliberada desordenar los planteamientos críticos que han ido adscribiendo una visión negativa de la conquista al siglo XIX, con la consiguiente construcción de una novedosa memoria histórica capaz de desligar, a los españoles americanos, del pasado hispánico surgido de la conquista o incluso de proponer poderosas líneas de análisis que seguían la pista del «patriotismo» criollo a lo largo de todo el virreinato dibujando un panorama extraño a los textos en que, fundamentalmente, autores españoles, fueran españoles americanos o españoles europeos, articulaban un pensamiento definido más que por su época y por sus ideas por su lugar de nacimiento. No es mi intención, repito, ese desorden, sino que así de variadas se manifiestan las posturas en los textos literarios, históricos o políticos que presento. Como podrá comprobarse, la selección de textos no parte de una lectura totalizadora del periodo, pero creo que esto puede convertirse en significativo ya que es un hecho que, sólo haciendo lecturas azarosas de distintos autores, empiece la variedad de posturas a resistirse a ser clasificadas según las ideologías marcadas por la crítica convencional (un pensamiento conservador y uno liberal separado, entre otras cosas, por su grado de vinculación con España), cronologías (un pensamiento dominante durante la colonia y otro durante el siglo XIX) o nacionalidades (unas posturas más o menos críticas con la conquista según el origen criollo o peninsular del autor). Creo, además, que las divisiones tajantes no provienen tanto de los planteamientos que surgieron al calor de la guerra de Independencia (tan variados son) como de una crítica histórico-literaria del siglo XX particularmente tendente a clasificar con esquemas patriótico-románticos (que ni siquiera hacen justicia al bullente siglo XIX americano) todas las producciones literarias de la América hispánica.

El tratamiento dado a la figura del conquistador permite observar las posiciones de los autores con respecto al origen de la historia hispánica del continente y las ligazones que establecieron los americanos con el orden hispánico, ya que no se entendería la carga sociológica del término «emancipación», que indistintamente se emplea para aludir a la Independencia, si no existiera una compleja relación metafórica, en los textos, entre los «padres» o «abuelos» españoles y los «hijos» o «nietos» americanos o criollos y si España, a parte de un país, no hubiera sido también un sentimiento variable entre el amor hacia la «madre» o el odio a la «madrastra».

José Joaquín Granados y Gálvez, franciscano oriundo de Málaga y asentado desde joven en Nueva España donde desarrollaría toda su carrera eclesiástica hasta llegar a ser obispo de Sonora, escribió un extenso diálogo, Tardes americanas (1778), en el que, sin velar su intencionalidad política de avisar de los trastornos que ocasionaban en América las novedades borbónicas, volcaba todos sus conocimientos históricos tanto del pasado

\section{Virginia Gil Amate}

Profesora Titular de Literatura Hispanoamericana de la Universidad de Oviedo. Es autora de la monografía Daniel Moyano, La búsqueda de una explicación (1993) y editora de los volúmenes Teatro de la emigración asturiana en Cuba (1997) y Escritores sin patria. La narrativa argentina de la segunda mitad del siglo $\mathrm{XX}$ (2006). Ha publicado diversos artículos sobre narrativa hispanoamericana contemporánea, sobre el pensamiento político de la independencia hispanoamericana y sobre cronistas de Indias, entre ellos el Inca Garcilaso de la Vega y Juan Suárez de Peralta.

\footnotetext{
La percepción de la figura del conquistador en textos hispanoamericanos de los siglos XVIII y XIX

VIRGINIA GIL AMATE
} 


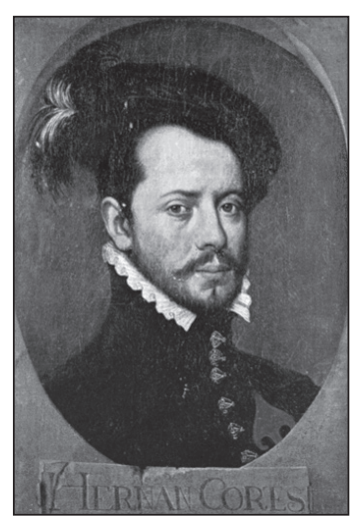

Hernán Cortés.

1

José Joaquín Granados y Gálvez, Tardes americanas, México Imprenta Matritense de D. Felipe de Zúñiga Ontiveros, 1778 «Introducción que sirve de prólogo», s.p.

2

Ibid., s.p.

3

lbid., p. 278.

Ibid., p. 276.

5

lbid., pp. 251-252.

6

lbid., p. 253.

7

Ibid., p. 260.

8

Ibid., pp. 256-257.

9

Tan cerrada le parece esta defensa de la conquista a Ramón Ezquerra que se pregunta si no será una ironía más del autor: Ramón Ezquerra, «La crítica española a la situación de América en el siglo XVII», Revista de Indias, 22: 87-88 (1962), p. 229.

La percepción de la figura del conquistador en textos hispanoamericanos de los siglos XVIII y XIX

VIRGINIA GIL AMATE indígena de México como de la historia del virreinato de Nueva España desde la conquista. La estructura ficcional se sostiene en la creación de tres personajes, un «Indio» y un «Español», que hablan de asuntos americanos en América, y un «Cura» amigo que actuará de amanuense para que lo hablado pueda ser leído en España. Ambos hablantes se muestran un tanto abrumados porque, según declara el «Indio»:

Vm. por Español, y yo por Indio, vendremos a ser el blanco de los pellizcos, araños, tarascadas y mordiscones, aun de los que no tienen uñas, y les faltan los dientes ${ }^{1}$.

El «Cura» también sospecha del nulo prestigio de los hablantes pero les anima a continuar pensando que el tema, los asuntos mexicanos, dignificará la empresa:

...á el que leyere con sana intención sus cláusulas, le agradarán: y la irrisión que causaren (por ser estudio de un Indio y un Español) la castigará con rectitud la dignidad de los Sujetos de quienes hablan².

El diálogo consta de una introducción y diecisiete «Tardes» o capítulos, que reparten la materia histórica equitativamente: ocho apartados para la historia indígena y ocho para la historia hispánica con un capítulo de cesura, la «Tarde nona», dedicado a la conquista. Granados, imbuido en la tradición franciscana, lamenta la dureza de la conquista hasta el punto de abrir la «Tarde» con una especie de sermón del «Español» sobre los males que ocasiona el ansia de riqueza y la nefasta influencia de la avaricia en los hombres que guía la lectura de un capítulo paradójico puesto que luego dará una batería de argumentos, que no razones, para marcar el carácter providencial de ésta y de Cortés como emisario divino. Hernán Cortés, que siempre fue alabado por los franciscanos, pocas veces llegó a verse tan rodeado de ditirambos como en Tardes americanas, donde resulta ser el «amante jardinero» ${ }^{3}$ del suelo mexicano, según el «Indio», si bien es cierto que lo está comparando con la «tirana dominación», la «malicia», el «espíritu de venganza» y en definitiva el «odio, discordia y atrevimiento» ${ }^{4}$ con que actuaron los conquistadores de a pie y los primeros pobladores de Nueva España.

La figura del Cortés que traza el hablante «Español», está marcada por la «animosidad, valor, intrepidez, acuerdo, prudencia, desin- terez, y todo espíritu de virtudes, que constituyen á un Varon ilustre y digno de la Posteridad $»^{5}$ por lo que se duele, y con esto vemos que el tema de las estatuas de Cortés es viejo aunque está un poco desorbitado en el padre Granados, de que «no haya merecido que en cada una de las casas, á lo menos de las de los Americanos, se tenga una estatua suya» ${ }^{6}$. A tal punto llega el fervoroso cortesianismo del «Español» que defiende, contra toda evidencia, la absoluta fidelidad marital de su héroe («Jamás quiso recibir muger, por guardar la fé del matrimonio ${ }^{7}$ ) y relata varios milagros con que la divinidad lo distinguió, éstos no tan extraños al discurso historiográfico del XVI pero si curiosos en una obra fechada a finales del siglo XVIII, cuando la censura cuidaba de los excesos que en materia de santidad pudieran cometer los autores.

Por supuesto, el sentido de un diálogo literario se extrae de las conclusiones a las que llegan los hablantes, y no de las argumentaciones e impugnaciones de la conversación. Teniéndolo en cuenta, debemos colegir que el retrato de Cortés termina siendo más que sobresaliente y por ello la conquista ha quedado salvada, no ya como episodio histórico sino, en la mentalidad de Granados, como la escritura derecha de Dios en reglones torcidos, porque el «Indio» no ha dejado de preguntarse por la crueldad de los conquistadores, en largas enumeraciones de estirpe lascasiana:

¿Quién creyera que un varón revestido del espíritu de verdadera religión, y conversión de las almas bárbaras, idólatras, y gentiles, había de predicar con la espada, y persuadir con el plomo, inundando los campos con las calientes púrpuras de las humanas vidas, y llenar los Pueblos, como los llenaron, de horror, turbaciones, escándalos, muertes, robos, despojos, ruinas, devastaciones, estrupos, odios, venganzas, crueldades, inobediencias, lamentos, clamores, lágrimas, y suspiros... ${ }^{8}$.

Ajeno a los problemas morales que el clero arrastró desde la conquista estaba otro español europeo, Alonso Carrió de la Vandera, al redactar en los capítulos XVI y XVII de El lazarillo de ciegos caminantes (1875 ó 76) una contundente defensa de la conquista ${ }^{9}$. Su diálogo, igualmente entablado por un indio y un español, recoge con gran amenidad una postura, no dos, sobre el proceso histórico. No es su intención detallar la historia de la conquista, sino defender a los españoles que poblaron el continente de los ataques que a esas alturas del siglo XVIII se habían con- 
vertido en un clamor en Europa ${ }^{10}$, y para ello no se adentra en terrenos éticos. Eso lo deja para los que llama «falsos piadosos» ${ }^{11}$. Para él están claros varios asuntos: primero, y en eso coincide no sólo con los hechos sino también con los textos de todos los cronistas de Indias, escribieran desde Europa o desde América, fueran soldados, capitanes, evangelizadores o historiadores, fueran indios, mestizos o europeos, que a la conquista contribuyeron, tanto en México como en Perú, los propios indígenas. «No debemos creer», dice Concolorcorvo, "que esta prodigiosa conquista se hubiese hecho solamente por el valor de los españoles» ${ }^{12}$; Segundo, y en esto no desdice a los evangelizadores, incluido Las Casas, que la conquista «fue conveniente a los indios, porque los españoles los sacaron de muchos errores y abominaciones que repugnan a la naturaleza» ${ }^{13}$, por supuesto la «naturaleza» a la que el Visitador se refiere en términos absolutos, remite a los concretos planteamientos católicos; Y tercero, que no son más crueles los españoles que cualquier otro individuo, y para ello utiliza, junto con la comparación, elemento común a todos los textos de autodefensa hispánica dieciochescos («Quisiera preguntar» dice el Visitador, «a los señores europeos, asiáticos y africanos, ¿qué alimento dan a sus forzados, que trabajan triplicadamente que éstos? ${ }^{14}$ ), otro de mayor interés, al señalar que la población europea de Indias no está compuesta sólo por españoles: «En todo este reino están esparcidos extranjeros, y no hemos experimentado en ellos más equidad, y aún nos gradúan a nosotros de demasiado indulgentes» ${ }^{15}$.

A Carrió de la Vandera el tema de la conquista le exaspera, "ya me tiene fastidiado» ${ }^{16}$ dirá su Visitador o más aún, «le consta a Vm. mi indiferencia en éste y otros asuntos» ${ }^{17}$, porque la mentalidad práctica que demuestra a lo largo de la obra casa con la autocrítica política (de ahí alguna de las bromas que inserta en los capítulos) pero no con el lamento melancólico. Para él, como para tantos en el siglo XVIII, hay una versión interesada de la conquista hecha al alimón por «extranjeros envidiosos» ${ }^{18}$ e «imprudentes» españoles ${ }^{19}$, que denigra a los antiguos conquistadores y esparce su sombra sobre toda la población americana de origen hispánico, y así, con ecos que recuerdan al Inca Garcilaso defendiendo a los «vezinos», declara:

No necesito satisfacer a los extranjeros, y menos a los españoles que habitan este continente, porque pue-

den con facilidad desengañarse 0 culparme de lisonjero y defensor acérrimo de los señores cozqueños. Confieso que estimo mucho a estos por su probidad y generosidad en este género de trato con sus colonos o súbditos ${ }^{20}$.

La magnífica Historia antigua de México (1780), del novohispano Francisco Javier Clavijero, ha sido repetidamente estudiada y señalada

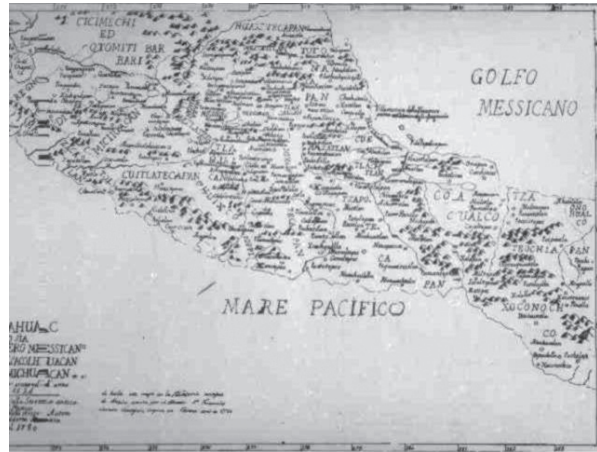

Mapa del Anáhuac en la Historia Antigua de México de Francisco Javier Clavijero. como la obra capital que re-

coge un sentir histórico criollo y, francamente, yo no consigo aislar ese definido espíritu mexicano que ha sido, por lo demás tan minuciosamente explicado, por grandes investigadores ${ }^{21}$. Debe ser una particular incapacidad mía para las cuestiones nacionales la que me impide comprender dónde rompe Clavijero con lo que, por oposición, se ha denominado «historiografía española». Sin embargo no soy ajena a los valores de la obra que hacen del autor el más grande historiador de Indias del siglo XVIII y uno de los mejores dentro del corpus de la historiografía indiana. Clavijero, con un estilo brioso y claro, una hermosa prosa, un uso crítico y razonado de las fuentes y un poderoso sentido de su labor como historiador, labra, en los capítulos que dedica a la conquista, una ajustada e inteligente narración ${ }^{22}$. En ella traza retratos físicos y morales de sus protagonistas, si atendemos a la semblanza de Cortés, Clavijero destaca en él las luces y las sombras morales de los guerreros, de los hombres de acción. Así subraya «su buen entendimiento», «su singular valor y destreza en todo tipo de armas», "su genio fecundo», el carisma con el que ejercía el mando, la magnanimidad que regía sus «designios $\mathrm{y}$ acciones», sus firmes creencias religiosas y su lealtad al monarca, virtudes que sin embargo no le impidieron realizar «algunas acciones indignas de la grandeza de su alma». Entre sus defectos alude a «su amor desordenado por el bello sexo", su ambición desmedida y una marcada tendencia hacia la obstinación que en ocasiones lo conducían al ofuscamiento, aún así, Clavijero se pregunta «¿qué conquistador

12 Ibid., p. 149.

13 Ibid., p. 150.

14 lbid., p. 157.

15 Ibid., p. 156.

16 Ibid., p. 151.

17

Ibid., p. 150

18 lbid., pp. 145, 147 y 150.

19 Ibid., p. 145. 20 lbid., p. 158

21

Alfonso Martínez Rosales (ed.) Francisco Xavier Clavijero en la ilustración mexicana, 17311787, México, El Colegio de México, 1988; David A. Brading, Orbe indiano. De la monarquía católica a la República criolla 1492-1867, México, Fondo de Cultura Económica, 1991.

22

Más allá de que ni siquiera el padre Clavijero haya salido indemne a las ironías de Antonello Gerbi (La disputa del Nuevo Mundo. Historia de una polémica 1750-1900, México, Fondo de Cultura Económica, 1993).

10

Véase Ricardo García-Cárcel, La leyenda negra. Historia y opinión, Madrid, Alianza Editorial, 1998 ( $1^{\mathrm{g}}$ ed. 1992).
11

Alonso Carrió de la Vandera, El lazarillo de ciegos caminantes, Caracas, Biblioteca Ayacucho, 1985, p. 156.

\footnotetext{
La percepción de la figura del conquistador en textos hispanoamericanos de los siglos XVIII y XIX

VIRGINIA GIL AMATE
} 
Francisco Javier Clavijero, Histo ria antigua de México, México, Porrúa, 1991, p. 297.

24

Ibid., p. 305.

25

Ibid., p. 356.

26

Ibid., nota 36, p. 327.

27

En el prólogo ajustó los márgenes en los que se movería como historiador, cláusulas y apreciaciones que repite en el pasaje anotado: "Al referir los acontecimientos de la conquista que hicieron los españoles, me aparto igualmente del panegírico de Solís que de la invectiva del ilustrísimo señor Las Casas, porque no quiero adular a mis nacionales ni tampoco calumniarlos» (ibid., "Prólogo del autor», p. XXII).

28

Ibid., nota 1, p. 379.

29

Ibid., p. 364.

30

lbid., p. 418.

31

Victorián de Villalba, Apuntamientos para la reforma del reino, en José Luis Romero y Luis Alberto Romero, selec., notas y cronol.; José Luis Romero, pról., Pensamiento político de la Emancipación (1790-1825), Caracas, Biblioteca Ayacucho, 1977, vol. I, p. 61.

32

José Martín Félix de Arrate, Llave del Nuevo Mundo, antemural de las Indias Occidentales, México, Fondo de Cultura Económica, 1949 , p. 95.

33 lbid., p. 97
La percepción de la figura del conquistador en textos hispanoamericanos de los siglos XVIII y XIX

VIRGINIA GIL AMATE formado en la escuela del mundo ha poseído jamás el heroísmo sin graves defectos?» ${ }^{23}$.

A esas alturas del siglo XVIII, Clavijero, religioso al fin, no está exento de contemplar la conquista como parte de un plan providencial:

No pretendemos por esto justificar la intención y la conducta de los conquistadores; pero tampoco podemos menos de reconocer en la serie de la conquista, a pesar de la incredulidad, la mano de Dios que iba disponiendo las cosas de aquel imperio a su ruina y se servía de los mismos aciertos de los hombres para los altos fines de su Providencia ${ }^{24}$.

Por eso no juzga sino expone, cotejando las fuentes, su narración de los hechos, en la que tanto destaca las artimañas que le parecen inmorales de Cortés y sus aliados, como muestra al capitán español contenido en la campaña militar por compasión hacia sus enemigos. En episodios extremadamente violentos de la conquista reclama "pruebas concluyentes» ${ }^{25}$, y en casos concretos como los sucesos de Cholula, no se deja llevar por el potente discurso lascasiano y declara, en nota a pie de página:

Para creer al señor Las Casas que los españoles ejecutaron aquel estrago solamente por antojo, $y$ que, al tiempo de derramar los soldados arroyos de sangre, el general estaba cantando coplas, sería menester que lo depusiese como testigo ocular, o que produjese documentos que borrasen la idea que nos dan de Cortés cuantos le conocieron, e hiciesen verosímil lo que absolutamente es increíble. Yo no dudo que escribió sobre el informe de alguno de los muchos enemigos de Cortés. No soy panegirista de este conquistador para encubrir sus defectos; pero soy historiador para no acriminarlo contra verdad y justicia, y soy cristiano para no creer tan grandes maldades de un individuo de mi especie sin graves fundamentos ${ }^{26}$.

Si no se inclina hacia Las Casas, porque es historiador, tampoco sigue mucho a Solís, ya dijo que no era panegirista ${ }^{27}$. Sus fuentes son las crónicas escritas por españoles e indios y, además, apuntará en otra ocasión, no va a buscar en voces extrajeras la información que puede encontrar en «nuestros historiadores nacionales Herrera, Torquemada y otros» ${ }^{28}$.

En definitiva, Clavijero narrará la conquista de México como una gesta comandada por españoles y auspiciada por diversos pueblos indígenas, seguida de un orden hispánico surgido de la conquista por la «cesión» ${ }^{29}$ que Moctezuma hizo de su reino a los monarcas cristianos, en la que los indígenas no hallarían el acomodo ansiado sino el «desprecio» de los españoles y, en un final sorprendente del libro añadirá a ese desdén el «de los más viles esclavos africanos y de sus infames descendientes». Con ello, según Clavijero, vengaba Dios «en la miserable posteridad de aquellas naciones la crueldad, la injusticia y la superstición de sus mayores» ${ }^{30}$.

Diecisiete años después de escrita esta historia, de nuevo un español europeo, Victorián de Villalba, que fue fiscal de la Audiencia de Charcas, caracterizaba en sus Apuntamientos para la reforma del Reino (1797) a los conquistadores de América como individuos particularmente soberbios que sometieron a unos inocentes americanos, término que $\mathrm{Vi}$ llalba emplea como sinónimo de indígenas o indios, y al cargo suma a los descendientes de los conquistadores:

Los conquistadores, los que les sucedieron y sus descendientes, creyéndose de una naturaleza superior a los demás hombres por sus proezas militares con unos entes aturdidos y preocupados que no sabían resistirlas, se persuadieron que los americanos les eran destinados para bestias de carga; y así los repartieron como ganado para hacerlos trabajar en los campos y en las minas: de modo que los que no habían fenecido al filo de la espada, fenecieron al de la opresión y la fatiga, más exterminador aunque lento ${ }^{31}$.

Bien diferente era la historia de Cuba que hacía 1761 redactó José Martín Félix de Arrate con ánimo de demostrar que la población de Indias no se había formado, en origen, con lo peor de España y por tanto, en su presente, no eran los americanos un conglomerado de bárbaros. Para Arrate la conquista no fue sólo «incentivo de espíritus vulgares sino de ánimos nobles y corazones generosos» ${ }^{32}$, centrando su aristocrático interés en destacar el paso a Indias, desde la conquista, de hijos de las más ilustres familias españolas que han llenado el Nuevo Mundo «del esplendor y honra de linajes muy esclarecidos» ${ }^{33}$. Con ello defendía Arrate su propia estirpe y a la par, no le cabía duda de ello, defendía a América de las visiones sesgadas que propios y extraños lanzaban sobre ella.

Críticas también tenía pero de otra índole, el jesuita novohispano Andrés Cavo, aunque no llegó a tanto como Villalba cuando redactó Los tres siglos de México durante el gobierno 
español hasta la entrada del ejército trigarante ${ }^{34}$, declarando que «la libertad con que escribo es la de un historiador que no sigue partido» ${ }^{35}$, en la que se lamentaba de la pérdida cultural que acarreó una conquista hecha en nombre de la fe pero dejada en manos de «ignorantes» que «destruyeron a sangre y fuego todo lo que juzgaba tenía alguna relación á la supersticiones de aquellas naciones» ${ }^{36}$. Opinión extendida ésta que molestaba a otros criollos, entre ellos a Juan José de Eguiara y Eguren quien, en el prólogo IV a la Biblioteca Mexicana, no dudó en cortar una cita de las Actas de Leipzig, donde se aludía a los escasos vestigios de la cultura indígena que dejó a su paso la violenta «ignorancia hispana», para contrarrestar lo que siente como una ofensa en carne propia:

...cantinela esta que sin cesar lanzan contra nosotros los extrajeros y que el deán alicantino no tiene empacho en repetir mil veces a carrillos inflados ${ }^{37}$.

El relato de Cavo trata de ser una crónica «moderna» ${ }^{38}$ de la ciudad de México por lo que no se detiene en la conquista y avanza en el periodo de fundación de la Nueva España, aquél en que, según su apreciación, «el dominio de los Españoles en el reino de México estaba tan asegurado, que nada había de temer de aquellas naciones» ${ }^{39}$. En ese primer momento la actuación de Cortés y sus hombres hacia los indígenas oscilaba entre «el rigor» $\mathrm{y}$ «el buen trato» ${ }^{40}$, tónica que continúa hasta la llegada de las disposiciones de Carlos $\mathrm{V}$ anulando los repartimientos de conquista, momento en que dividirá a estos primeros pobladores en dos «partidos»:

...los hombres íntegros ensalzaban la determinación del Emperador de dar por libres a los Mexicanos como mandaba la equidad; al contrario los conquistadores que desfrutaban los repartimientos, prorrumpieron en expresiones poco decorosas á la majestad, tachando de injusticia manifiesta aquella sabia resolución, por privar de aquel beneficio a hombres que por su espada se lo habian ganado, y que con aquella providencia el mérito quedaba sin galardón; y como casi siempre sucede por vicio de la naturaleza humana, estos prevalecen al bien común, á fuerza de representaciones obligaron los mismos á Cortés á sobreseer en aquel punto, é informar al Rey de los inconvenientes que abultaban ${ }^{41}$.

Planteamiento bien distinto al que se encuentra en la Memoria póstuma (1808) del síndico del Ayuntamiento de México, Fran- cisco Verdad, para el cual la conquista fue una magnifica gesta de evangelización patrocinada por la corona que estuvo lejos de ser un buen negocio porque «en los primeros años de la conquista fueron gravosos estos dominios para la corona de Castilla» ${ }^{42}$ y siempre estuvieron los reyes más preocupados de proteger a los indios que de extraer minerales preciosos. Ninguno de los postulados en los que se asientan las ideas de Verdad era nuevo: en boga estaban desde el siglo XVII las posturas que aludían a Indias como un pesado fardo que España aguantaba desde la conquista, bien porque supusieron una despoblación de la península, bien porque no se supo administrar cabalmente el imperio. De sobra es conocida la frase de Feijoo, «el Oro de Indias nos tiene pobres» ${ }^{43} ; \mathrm{y}$, ni que decir tiene, que con más o menos énfasis habían destacado los cronistas desde el siglo XVI la expansión del cristianismo que favoreció el descubrimiento de América y su posterior colonización. En la argumentación de este postulado algunos tuvieron cuidado en desmarcar a la corona de los desmanes producidos en Indias. Sirva como ejemplo, para el siglo XVIII, el alegato de José Eusebio del Llano Zapata, en cerrada defensa de los reyes de España y en particular de Fernando VI:

Quiero decir en esto que en todo tiempo ha sido sana la intención de Nuestros Cathólicos Monarcas con aquellas gentes: y mas en el presente Systhema en que todo es virtud, todo religión, todo christiandad el Soberano, que nos govierna ${ }^{44}$.

Para el ilustre criollo peruano, cualquier «viagero juicioso» que quisiera estudiar las cuestiones naturales no debería, sin conocimientos, inmiscuirse en temas históricos y políticos, porque terminará agrediendo a un tiempo a los americanos, al monarca y al Papa, y denigrando al sistema político y cultural del que él, que fue un incontestable paladín de los indígenas, forma parte:

...debe dexar á otras plumas las odiosas reflexiones de Conquistas. Hé leído a algunos Authóres tan imprudentes, y atrevidos, que haciendose arbitros de la justicia, se mezclan en derechos de la Dominación, que no entienden. Si fueran Estrangéros no me admirara. Las plumas nuestras nos desacreditan. De ellas se vale la envidia para morder á Nuestra Nacion, que tanto ha trabajado, y trabaja en cultivar la de los Indios. No es culpa del Monarcha el desacierto del Vasallo. $\mathrm{Ni}$ menos tiene parte la Soberania en los insultos, que comete la ambición. Esto era querer
34

Andrés Cavo, Los tres siglos de México durante el gobierno es pañol hasta la entrada del ejército trigarante, México, Imprento de Luis Abadiamo Valdés, 1836. Los dos primeros volúmenes corresponden a la obra de Andrés Cavo, el tercer tomo, a partir del Libro 13, es el «Suplemento» con el que Bustamante decidió continuar la historia del padre Cavo a partir de 1767, año en que se detenía el trabajo del jesuita expulso.

35 Ibid. Prólogo, Tomo 1, p. 1

36

Ibid., Tomo 1, Libro I, ap. 8, p. 8.

37

Juan José de Eguiara y Eguren Prólogos a la Biblioteca Mexicana, México, Fondo de Cultura Económica, 1994, p. 83.

38

Cavo, op. cit., Prólogo, Tomo 1, p. 1.

39

Ibid., Tomo 1, Libro I, ap. 14 p. 17.

40

Id.

41

Ibid., Tomo 1, Libro I, ap. 21, p. 24 .

42

Francisco Verdad, Memoria póstuma, en Romero, Pensamiento político..., op. cit., vol. I, p. 92

43

Benito Jerónimo Feijoo, «Fábula de las Batuecas y paises imaginarios", Theatro crítico universal, Madrid, Real Compañía de Impresores y Libreros, 1769 discurso X, Tomo IV, p. 266

44

Joseph Eusebio del Llano Zapata, Preliminar y cartas que preceden al tomo I de las Memorias histórico-physicas, critico-apologeticas de la América Meridional, Cádiz, Oficina de D. Pedro Gómez de Requena, 1758, "Artículo preliminar», p. 4.

\footnotetext{
La percepción de la figura del conquistador en textos hispanoamericanos de los siglos XVIII y XIX

VIRGINIA GIL AMATE
} 


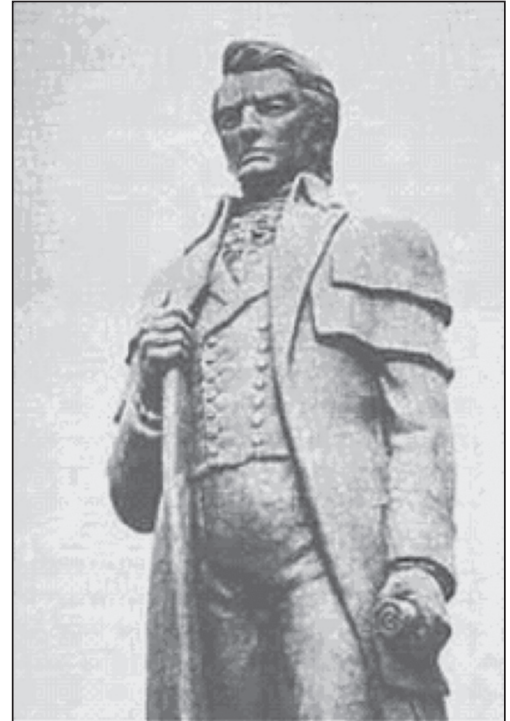

Monumento a Juan Pablo Viscardo y Guzmán.

manchar el Solio, y vituperar en esta parte las empressas con descredito de la Magestad, que las integra. En estos tiempos han escrito varios de los Nuestros, que por su character y estado debian ser mas contenidos en sus plumas. En sus papeles ó caprichos impressos hán amontonado armas de que se sirven todas las Naciones, para decir mal de Nuestros trabajos en la enseñanza, y redencion de aquellas gentes, desfigurando la verdad de los hechos con la máscara de piedad, y religión ${ }^{45}$.

De este modo va aflorando en cada línea del preliminar que redactó para sus Memorias históricophysicas, crítico-apologéticas de la América Meridional (1756), la fuerte desazón que le provocan las noticias que andan, en su presente, esparcidas sobre América y su pasado, y eso

45 Ibid., p. 2.

46 Ibid., p. 3.

47

Véase Miquel Batllori, El abate Viscardo. Historia y mito de la intervención de los jesuitas en la Independencia de Hispanoamérica, Madrid, Maphre, 1995 (1 ${ }^{\text {a }}$ ed. 1953).

48

Ibid., p. 326. Citamos por la reproducción de la traducción al español de la Carta editada en Londres, P. Boyle, 1801, dada por Batllori.

49

Id.

50

Ibid., pp. 327 y 355

51

Ibid., p. 359

52

Ibid., pp. 326-327.

53

Ibid., p. 334.
La percepción de la figura del conquistador en textos hispanoamericanos de los siglos XVIII y XIX

VIRGINIA GIL AMATE que faltaban todavía dos décadas para que Marmontel publicara Les Incas, porque, para Llano Zapata, ocultan la realidad e infaman a la propia población de Indias:

...ocultando baxo del velo de la charidad, una supersticiosa hypocresía, en vez de historias esparcieron chiméras y en lugar de noticias derramaron libelos, que afrentosamente nos calumnian ${ }^{46}$.

Hasta ahora hemos podido ver varias posturas a la hora de afrontar la conquista: los que la consideraron positiva, sin hacerse mayor problema o con serias dudas morales, los que apostaban por narrarla sin pasión, asumiendo o aceptando la historia, o los que la denunciaban como un hecho atroz continuado en el tiempo. Ninguno de los aludidos asumía el pasado histórico como un problema de índole personal tal cual aparecerá en algunos textos de finales del siglo XVIII y principios del XIX, cuando los sucesos históricos vividos por sus autores, no la conquista, obliguen a los criollos a definirse frente a España. Por ejemplo, la condición vital en la que se encontró Juan Pablo Viscardo ${ }^{47}$, a raíz de la expulsión de los jesuitas de todos los reinos españoles, guía los fragmentos de reflexión identitaria que hay en su Carta a los españoles americanos (1792). Comienza su texto con una declaración en la que está implícita, más allá de las críticas al mal gobierno de la Corona en Indias, la ligazón de los criollos con la conquista: «El nuevo-mundo es nuestra patria, su historia es la nuestra» ${ }^{48}$. Los conquistadores serán llamados «nuestros antepasados $»^{49} \mathrm{O}$ «nuestros padres» ${ }^{50}$. No hay por tanto en la carta, que sin embargo es un llamamiento a la independencia ( La naturaleza nos ha separado de la España con mares inmensos. Un hijo que se hallaría a semejante distancia de su padre sería sin duda un insensato, si en la conducta de sus más pequeños intereses esperase siempre la resolución de su padre. El hijo está emancipado por el derecho natural» ${ }^{51}$ ), un planteamiento disímil al que Francisco de Terrazas estableció en el siglo XVI en su Nuevo Mundo y conquista. El hijo, para seguir con la metáfora, lamenta, allí y aquí, la ingratitud, si bien es cierto que Terrazas se quejaba de la «madre», Nueva España, y Viscardo alude al «padre» español. A partir de ahí el texto crece en paradojas, porque la conquista podrá ser referida a través de las hazañas que realizaron los conquistadores:

Quando nuestros antepasados se retiraron à una distancia inmensa de su pays natal, renunciando no solamente al alimento, sino tanbién a la protección civil que allí les pertenecía, y que no podia alcanzarles à tan grandes distancias, se expusieron, à costa propia, à procurarse una subsistencia nueva, con las fatigas mas enormes, y con los mas grandes peligros. El gran suceso que coronó los esfuerzos de los conquistadores de América, les daba, al parecer, un derecho, que aunque no era el más justo, era a lo menos mejor, que el que tenían los antiguos Godos de España, para apropiarse el fruto de su valor, y de sus trabajos ${ }^{52}$.

$\mathrm{O}$, al cruzarse con los hechos del presente de Viscardo, el autor no sepa si la condena por bárbara o la celebra por extraordinaria o si el conquistador es, según el párrafo, el heroico padre o el avaricioso tirano:

Afin de que nada faltase à nuestra ruina, y à nuestra ignominiosa servidumbre, la indigencia, la avaricia y la ambición han subministrado siempre a la España un enjambre de aventureros, que pasan a la América resueltos a desquitarse alli, con nuestra sustancia, de lo que han pagado para obtener sus empleos. La manera de indemnizarse de la ausencia de su patria, de sus penas, y de sus peligros, es haciendonos todos los males posibles. Renovando todos los dias aquellas escenas de horrores que hicieron desaparecer pueblos enteros, cuio unico delito fue su flaqueza, convierten el resplandor de la más grande conquista, en una mancha ignominiosa para el nombre Español ${ }^{53}$.

Muchas quejas, aunque estas bastante mejor argumentadas, tenía también que expresarle a España, en nombre del Cabildo de 
Santa Fe de Bogotá (que finalmente archivó su escrito), el neogranadino Camilo Torres. La crisis política que la invasión francesa causó en la península y los reinos ultramarinos es el suceso histórico que propició la redacción del documento que con posterioridad se conocería con el nombre de Memorial de agravios (1809). Con prosa firme procede el síndico a enumerar las perniciosas consecuencias que el mal gobierno de España ha ocasionado en América, con ánimo de apuntar las causas para buscarles remedio y todo ello hecho en condición de lealtad a la corona, patriotismo hispánico que por lo demás está presente en buena parte de los escritos políticos americanos durante la primera década del siglo XIX, sea para ofrecerles el territorio americano como sede a los monarcas españoles o sea, y esto nos interesa más, para brindarles un recibimiento fraternal a los españoles que deban abandonar la península:

¡Qué consuelo será para nuestros hermanos y amigos los españoles (decía Fray Melchor de Talamantes en su Idea del congreso nacional de Nueva España de 1808, cuando justificaba la creación de un gobierno autónomo apoyado por el virrey Iturrigaray), saber que viniendo a México encontrarán aquí una nueva patria, con las mismas leyes, usos y costumbres y religión, y que serán recibidos con aquella predilección $\mathrm{y}$ ternura que inspiran las desgracias de las personas que nos son amadas ${ }^{54}$ !

Y no podía ser de otra manera porque, en el caso concreto del Memorial de agravios, cuando la sustancia de contenido se detiene en la historia, declara a los criollos descendientes, con orgullo, de los conquistadores:

Las Américas, Señor, no están compuestas de extranjeros a la nación española. Somos hijos, somos descendientes de los que han derramado su sangre por adquirir estos nuevos dominios a la corona de España; de los que han extendido sus límites y le han dado en la balanza política de la Europa, una representación que por sí sola no podía tener. Los naturales conquistados y sujetos hoy al dominio español, son muy pocos o son nada en comparación de los hijos de europeos que hoy pueblan esas ricas posesiones. La continua emigración de España, en tres siglos que han pasado desde el descubrimiento de la América; la provisión de casi todos sus oficios y empleos en españoles europeos que han venido a establecerse sucesivamente, y que han dejado en ellas sus hijos y su posteridad, las ventajas del comercio y de los ricos dones que aquí ofrece la naturaleza, han sido otras tantas fuentes perpetuas, y el origen de nuestra población. Así, no hay que engañarnos en esta parte: tan españoles somos como los descendientes de Don Pelayo y tan acreedores, por esta razón, a las distinciones, privilegios y prerrogativas del resto de la nación, como los que, salidos de las montañas, expelieron a los moros y poblaron sucesivamente la península; con esta diferencia, si hay alguna, que nuestros padres, como se ha dicho, por medio de indecibles trabajos y fatigas, descubrieron, conquistaron y poblaron para España este Nuevo Mundo ${ }^{55}$.

Cuando el hecho histórico que protagonice Simón Bolívar sea la guerra de Independencia, la relación criolla con la conquista y los conquistadores será definida como un problema de difícil resolución. Por eso la misma cuestión es abordada en la Carta de Jamaica, fechada en 1815, como en el Discurso de Angostura, de 1819. Los términos, en lo que a la conformación identitaria se refiere, son similares no así los matices de orden político que han variado de uno a otro documento:

...nosotros, que apenas conservamos vestigios de lo que en otro tiempo fue, y que por otra parte no somos indios ni europeos, sino una especie media entre los legítimos propietarios del país y los usurpadores españoles: en suma, siendo nosotros americanos por nacimiento, y nuestros derechos los de Europa, tenemos que disputar éstos a los del país y que mantenernos en él contra la invasión de los invasores; así nos hallamos en el caso más extraordinario y complicado ${ }^{56}$.

...no somos europeos, no somos indios, sino una especie media entre los aborígenes y los españoles. Americanos por nacimiento y europeos por derechos, nos hallamos en el conflicto de disputar a los naturales los títulos de posesión y de mantenernos en el país que nos vio nacer, contra la invasión de los invasores ${ }^{57}$.

Al contemplar la heterogeneidad de la población de la América hispánica, Bolívar comparte con Camilo Torres la tendencia a no calibrar en su justa medida el tanto por ciento que ocupa la población indígena, y desarrolla, con tintes novedosos para la segunda década del siglo XIX, la común metáfora filial. Para el Libertador todos los americanos comparten una misma «madre», la tierra americana; y todos son hijos de variados «padres» extranjeros:

Es imposible asignar con propiedad a qué familia humana pertenecemos. La mayor parte del indígena

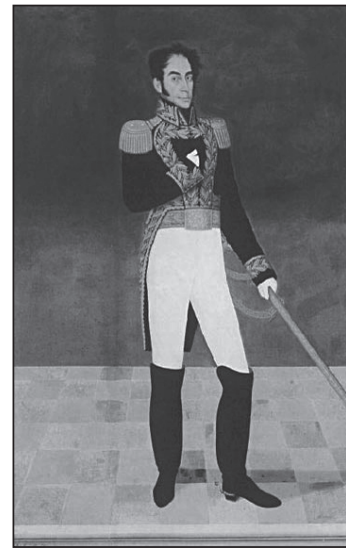

Retrato de Simón Bolívar en Lima, 1825. José Gil de Castro. Salón Elíptico del Congreso $\mathrm{Na}$ cional, Caracas, Venezuela.

54

Melchor de Talamantes, Idea del Congreso Nacional de Nueva España, en Romero, Pensamiento político..., op. cit., vol. I, p. 96

55

Camilo Torres, Memorial de agravios, en ibid., vol. I, p. 29.

56

Simón Bolívar, "Carta de Jamaica», en Doctrina del Libertador Augusto Mijares, pról.; Manuel Pérez Vila, comp., notas y cronol., Caracas, Biblioteca Ayacucho, 1985.

57

Simón Bolivar, «Discurso de Angostura», en ibid., p. 104

\footnotetext{
La percepción de la figura del conquistador en textos hispanoamericanos de los siglos XVIII y XIX

VIRGINIA GIL AMATE
} 
59

Simón Bolívar, "Carta al General Santander»(23-I-1824), en ibid., p. 175

60

Término utilizado por Simón Bolívar en la "Carta de Jamaica», en ibid., p. 55

61

Manuel Lorenzo de Vidaurre, «Entretenimento II», Plan del Perú y otros escritos, en Alberto Tauro del Pino (ed.), Colección documental de la Independencia del Perú, Lima, Comisión Nacional del Sesqicentenario, 1971 tomo I, vol. 5, p. 216

62

Agustín de Iturbide, Proclama y plan de Igualada, en Romero, Pensamiento político..., op. cit. vol. II, p. 284.

63

Miguel Hidalgo, Manifiesto (diciembre de 1810), en ibid., p. 43

64

José Cecilio del Valle, Diálogo de diversos muertos sobre la Independencia de América, en ibid., p. 251

65

Rafael Núñez, La reforma política, en José Luis Romero y Luis Alberto Romero, sel., notas y cronol.; José Luis Romero, pról., Pensamiento conservador (1815-1898), Caracas, Biblioteca Ayacucho, 1978, p. 80.
La percepción de la figura del conquistador en textos hispanoamericanos de los siglos XVIII y XIX

VIRGINIA GIL AMATE se ha aniquilado, el europeo se ha mezclado con el americano y con el africano, y éste se ha mezclado con el indio y con el europeo. Nacidos todos del seno de una misma madre, nuestros padres, difieren en origen y en sangre, son extranjeros, y todos difieren visiblemente en la epidermis; esta desemejanza trae un reato de la mayor trascendencia ${ }^{58}$.

Si el «padre» de los indígenas queda un tanto desenfocado, el particular «padre» de los criollos no queda bien parado, porque la negativa categoría que ocupa el español se remonta al origen. "Malditos reconquistadores» ${ }^{59}$ llamará al bando realista en carta al general Santander. A partir de ahí algunos poemas patrióticos de gran éxito apuntalarán una visión en la que el conquistador no será aquel que forjó el Nuevo Mundo sino el «destructor» ${ }^{60}$ de América. No hay en la literatura, al menos en la poesía que ejemplifica $L a$ victoria de Junín. Canto a Bolivar (1825), de José Joaquín de Olmedo, los escollos críticos de difícil definición que había en los autores de prosa política. Los cantos cívicos venían a apoyar una memoria histórica desgajada de la conquista que ni siquiera había sido uniforme en el periodo de guerra, de ahí que en Perú, en 1810 , se dejaran oír voces como la de Manuel Lorenzo de Vidaurre mostrándose contrario a la imagen que se proyectaba de los conquistadores:

Estas crueldades de los españoles con los indios ¿̨o son de nuestros abuelos y tíos? ¿Acaso descendemos de hombres diversos? ¿Qué delito les imputaremos que no recaiga sobre nosotros ${ }^{61}$ ?

O en México, Agustín de Iturbide en su Proclama y plan de Igualada (1821) preguntara retóricamente a los americanos, "¿quién de vosotros puede decir que no desciende de español» ${ }^{62}$ ?, mientras Hidalgo y Morelos decretaban la guerra a muerte a los gachupines, que para Hidalgo eran, entre otras cosas, los que durante generaciones habían abandonado a sus familias en España, dislocando, en su Manifiesto de 1810, el canon familiar criollo no ya de los hispanófilos sino de los mismos libertadores:

Os persuadís, amados conciudadanos, que los gachupines, hombres desnaturalizados, que han roto los más estrechos vínculos de la sangre, ¡se estremece la naturaleza! Que abandonando a sus padres, a sus hermanos, a sus mujeres, a sus propios hijos, sean capaces de tener afectos de humanidad a otras personas? ¿Podéis tener con ellos algún enlace, superior a los que la misma naturaleza puso en las relaciones de familia? ¿No los atropellan todos por solo el interés de hacerse ricos en América? Pues no creáis que unos hombres nutridos de estos sentimientos puedan mantener amistad sincera con nosotros: siempre que se les presente el vil interés, os sacrificarán con la misma frescura que han abandonado a sus propios padres. ¿Creéis que el atravesar inmensos mares, exponerse al hambre, a la desnudez, a los peligros de la vida, inseparables de la navegación, lo han emprendido por venir a hacernos felices? Os engañáis, americanos... ${ }^{63}$.

Siguiendo con las curiosidades, José Cirilo del Valle, en su Diálogo de diversos muertos sobre la Independencia de América (1821), hizo conversar, entre otros, a Carlos I con Carlos III, es decir, al rey absoluto con el rey ilustrado, al monarca de la organización virreinal frente al de la reforma del reino, y de la rara combinación sale que al Borbón no le sobresalta la Independencia porque la verá como un proceso natural de emancipación:

La independencia no será entonces la reacción del oprimido que se vuelve con saña contra el opresor. Será la emancipación del hijo que llegado a la edad viril se aparta de la casa del padre, reconocido a la beneficencia que supo darle educación y fuerzas ${ }^{64}$.

De igual modo la vería, ya en el último cuarto del siglo XIX, el colombiano Rafael Núñez, en La reforma política (1881-1883), donde contemplaba con cuanta «frecuencia hacemos los hispanoamericanos terribles cargos a la dominación peninsular, sin reconocerles casi un solo título de gratitud del Nuevo Mundo. Encontramos eclipsada por los dolores de la conquista la portentosa labor del descubrimiento", y para Núñez no debería ser así por un sencillo, incluso perogrullesco, razonamiento causal:

¿Y quiénes fueron los iniciadores de la Independencia? Fueron (todos lo sabemos) los descendientes de los mismos conquistadores. La Independencia fue, por tanto, el desarrollo lógico, providencial, aunque lento, de la conquista; como esta fue derivación, mucho más rápida, del descubrimiento. Suprimida la conquista, quedaría también, por consiguiente, suprimido el 20 de julio de 181065 .

También la conquista y la independencia están unidas por Olmedo pero en un sentido ideológico opuesto al de Núñez, en el momento en que Huayna Cápac, en las zonas centrales del poema, llama «hijos» a los liber- 
tadores y los convierte en los vengadores de la causa indígena. Algo parecido hacía Bernardo O’Higgins en su Proclama a los araucanos (1818), guiada en este caso por una motivación más utilitaria y concreta que la construcción de una memoria histórica, como era la de conseguir que los indígenas del sur retiraran su apoyo al bando realista y se unieran a los criollos bajo la idea de que «descendemos todos de unos mismos padres» ${ }^{66}$.

No militaba en ese bando otro ilustre criollo, Mariano de Beristáin y Souza que defendía con pasión, incluso temeraria ${ }^{67}$, el buen nombre de España, su gesta conquistadora, el cariz católico que hacía noble a la empresa y la filiación hispánica de los criollos.

Fuera como fuera, Núñez reconocía «que la impresión que prevalece [sobre la conquista] es, por lo general, de antipatía y aún de horror e indignación ${ }^{68}$, ¿̇no será esa, me pregunto para terminar, la impresión fijada como la mirada americana sobre el pasado, aunque no fuera la única, ni fueran marginales, ni indeseables, ni enemigos de la causa americana, los que escribieron sobre las cosas de otra manera?

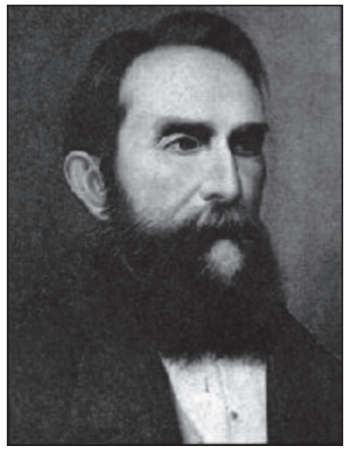

Rafael Núñez.

66

Bernardo O'Higgins, Proclama a los araucanos, en Romero, Pensamiento político..., op. cit., vol. II, p. 201

67

Parte de los contratiempos que a Beristáin le supuso alinearse en las filas realistas puede verse en José Carlos Rovira, «El bibliófilo Beristánin en una contienda poética desde los balcones a fines de 1796», en Varia de persecuciones en el XVIII novohispano, Roma, Bulzoni, 1999, pp. 104-127.

68

Núñez, op. cit., p. 80 